\title{
Redox-Active Metallacarborane-Decorated Octasilsesquioxanes. Electrochemical and Thermal Properties
}

\author{
Justo Cabrera-González, ${ }^{\dagger}$ Víctor Sánchez-Arderiu, $^{\dagger}$ Clara Viñas, $^{\dagger}$ Teodor Parella, ${ }^{\ddagger}$ Francesc Teixidor, ${ }^{\dagger}$ \\ and Rosario Núñez ${ }^{* \dagger \dagger}$ \\ ${ }^{\dagger}$ Institut de Ciència de Materials de Barcelona (ICMAB-CSIC), Campus de la Universitat Autònoma de Barcelona, 08193 Bellaterra, \\ Barcelona, Spain \\ ‡Servei de Ressonància Magnètica Nuclear, Universitat Autònoma de Barcelona, 08193 Bellaterra, Barcelona, Spain
}

\section{Supporting Information}

ABSTRACT: Polyanionic and electroactive hybrids based on octasilsesquioxanes bearing metallacarborane units are developed. They show remarkable solubility in organic solvents and outstanding thermal stability. The metallacarboranes act as independent units simultaneously undergoing the reversible redox process.

M etallodendrimers are metal-containing macromolecules that have attracted an increased interest in the development of nanometer-scale materials. ${ }^{1}$ The incorporation of redoxactive units into dendritic structures leads to a wide range of applications such as sensors, catalysts, biomedical materials, and multielectron storage devices, ${ }^{2,3}$ among others. Dendrimer-type molecules are ideal platforms to construct these devices, which must be designed to satisfy some conditions such as possessing robust and reversible redox moieties. ${ }^{4}$ Polyhedral octasilsesquioxanes (POSSs) are 3D scaffolds that, unlike most dendrimers, are easy to synthesize and exhibit robustness, versatility in functionality, and high solubility. ${ }^{5,6}$ The inorganic core of POSS cages provides mechanical stiffness and thermal stability, whereas the organic pendant groups provide oxidative stability, as well as mechanical, optical, electrical, or electronic properties. ${ }^{7,8}$ These characteristics make POSSs promising building blocks for hybrid nanomaterials toward technological applications. $^{9-13}$ As a particular case, silsesquioxane-cored dendrimers bearing ferrocenyl units were reported to confer electroactive properties. ${ }^{14-16}$ However, an important drawback of some ferrocene $(\mathrm{Fc})$-functionalized silsesquioxane dendrimers is their lack of solubility in common solvents. ${ }^{17}$

Metallacarboranes $\left[\mathrm{M}\left(\mathrm{C}_{2} \mathrm{~B}_{9} \mathrm{H}_{11}\right)_{2}\right]^{-}$are unique redox-active molecules, in which a central metal ion, commonly Co (cobaltabisdicarbollide or COSAN) or Fe (ferrabisdicarbollide or FESAN), is $\eta^{5}$-bonded to two dicarbollide anions $\left[\mathrm{C}_{2} \mathrm{~B}_{9} \mathrm{H}_{11}\right]^{2-}$. ${ }^{18}$ In addition to their high thermal and chemical stability, ${ }^{19}$ metallacarboranes show unusual supramolecular interactions and self-assembling properties. ${ }^{20-22}$ Because of the presence of $\mathrm{Co}$ or $\mathrm{Fe}$, these complexes display one well-studied reversible wave under cyclic voltammetry $(\mathrm{CV})$ conditions, at $-1.74 \mathrm{~V}$ for $\mathrm{Co}^{3+/ 2+}$ in COSAN and at $-0.78 \mathrm{~V}$ for $\mathrm{Fe}^{3+/ 2+}$ in FESAN versus $\mathrm{Fc}^{23,24}$ Another remarkable property is the stepwise tuning of the redox potential upon dehydrohalogenation of the metallacarboranes..$^{25-27}$ Moreover, the ionic character of COSAN and FESAN provide them a high versatility to be soluble in a broad scope of organic and inorganic media by modification of the cation nature.

Our laboratory and others have contributed to the advancement of metallacarborane-containing dendrimers; ${ }^{28-31}$ however, a few studies have been carried out from an electrochemical viewpoint. $^{31}$ This paper does not specifically deal with electroactive metallodendrimers, but we will focus on conceptually similar large molecules but small enough to learn about their electron-transfer (ET) capacity with the electrode. Contrary to $\mathrm{Fc},{ }^{15,16}$ the investigation of silsesquioxanes functionalized with metallacarboranes has not yet been explored. Regarding the special electronic, physicochemical, anionic nature but lower charge densities of metallacarboranes on the one hand $^{32,33}$ and architecture properties of silsesquioxanes on the other, $^{5-8}$ the target here is to produce new multifunctional molecular materials to combine the unique properties of metallacarboranes with the robustness and stability of POSS. To this end, we report the synthesis and complete characterization of COSAN- and FESAN-terminated octasilsesquioxanes, combined with diffusion studies performed by CV and NMR spectroscopy in solution to determine their overall sizes; we also study the electrochemical behavior of the new materials to learn about their ET properties, and finally we analyze how the presence of metallacarboranes produces enhancement of the thermal stability.

The decoration of octavinylsilsesquioxane (OVS) was performed via a cross-metathesis reaction. ${ }^{34,35}$ Starting from $\left[3,3^{\prime}-\mathrm{Co}\left(8-\mathrm{C}_{4} \mathrm{H}_{8} \mathrm{O}_{2}-1,2-\mathrm{C}_{2} \mathrm{~B}_{9} \mathrm{H}_{10}\right)\left(1^{\prime}, 2^{\prime}-\mathrm{C}_{2} \mathrm{~B}_{9} \mathrm{H}_{11}\right)\right]$ and $\left[3,3^{\prime}-\right.$ $\left.\mathrm{Fe}\left(8-\mathrm{C}_{4} \mathrm{H}_{8} \mathrm{O}_{2}-1,2-\mathrm{C}_{2} \mathrm{~B}_{9} \mathrm{H}_{10}\right)\left(1^{\prime}, 2^{\prime}-\mathrm{C}_{2} \mathrm{~B}_{9} \mathrm{H}_{11}\right)\right]$, two new anionic precursors bearing a terminal styrene group ( 1 and 2 ) were synthesized by a nucleophilic oxonium ring-opening reaction using the deprotonated 4-vinylphenol as the nucleophile (Scheme 1A). The reaction was monitored by ${ }^{11} \mathrm{~B}$ NMR spectroscopy by comparison with their parent species, ${ }^{36,37}$ and compounds $\mathbf{1}$ and $\mathbf{2}$ were isolated as $\left[\mathrm{NMe}_{4}\right]^{+}$salts in $98.5 \%$ and $32 \%$ yield, respectively.

Cross-metathesis reactions of $\mathbf{1}$ and $\mathbf{2}$ with OVS were performed using the first-generation Grubbs's catalyst. Regioand stereoselective $E$ isomers of metallacarborane-containing POSSs 3 and 4 were obtained, isolating both compounds in $83 \%$ and $45 \%$ yield, respectively (Scheme 1B). The cross-metathesis

Received: October 5, 2016

Published: November 10, 2016 
Scheme 1. (A) Synthesis of Metallacarborane Derivatives 1 and 2 and (B) Cross-Metathesis Reactions To Obtain 3 and 4

A)

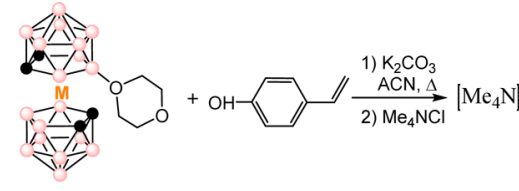

B)

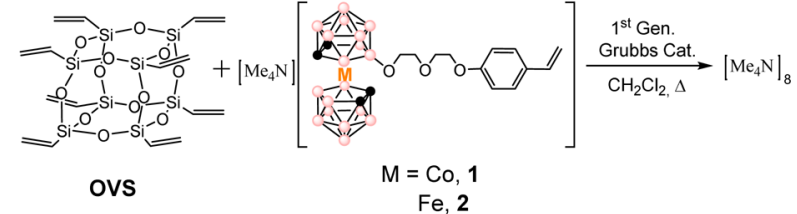

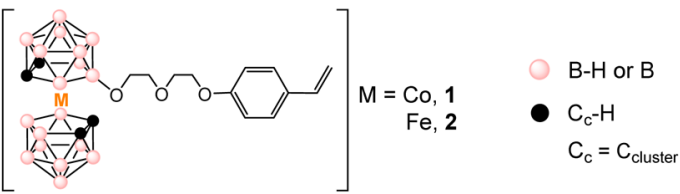

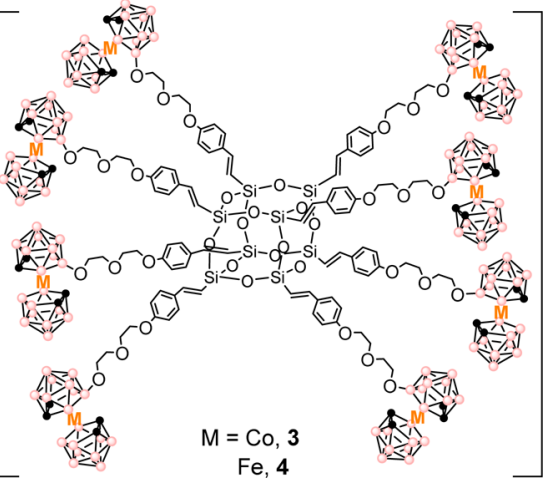

reactions were monitored by ${ }^{1} \mathrm{H}$ NMR upon the total disappearance of the vinyl proton resonances from $\mathrm{SiCH}=$ $\mathrm{CH}_{2}$ (Figure S2 in the Supporting Information, SI). Compounds 1-4 were characterized by attenuated total reflectance IR, NMR $\left({ }^{1} \mathrm{H},{ }^{1} \mathrm{H}\left\{{ }^{11} \mathrm{~B}\right\},{ }^{13} \mathrm{C}\left\{{ }^{1} \mathrm{H}\right\},{ }^{11} \mathrm{~B}\left\{{ }^{1} \mathrm{H}\right\}\right.$, and $\left.{ }^{11} \mathrm{~B}\right)$, and elemental analysis, whereas matrix-assisted laser desorption/ionization time-of-flight (MALDI-TOF) was possible only for $\mathbf{1}$ and $\mathbf{2}$ (see the SI).

To confirm the total functionalization of OVS, we used the method developed by Kim and Jung, ${ }^{38}$ as for previous COSANcontaining dendrimers, ${ }^{28-30,39}$ based on the estimation of the metallacarborane units by the Lambert-Beer law. Figure 1 shows the UV-vis spectra for 1-4 in acetonitrile and their line-fitting analysis with gaussians, for an adequate discernment of the spectral bands. ${ }^{40,41}$

The maximum at $260 \mathrm{~nm}$ for $\mathbf{1}$ and 2 , which is $15 \mathrm{~nm}$ redshifted in POSS cages 3 and $4(275 \mathrm{~nm})$, is mainly endorsed to the styrene group; the maxima, near 310 and $370 \mathrm{~nm}$, are attributed to metallacarboranes. ${ }^{30,40}$ Therefore, the number of metallacarboranes for $\mathbf{3}$ and $\mathbf{4}$ was estimated by comparing their molar extinction coefficients $(\varepsilon)$ for deconvoluted curves at
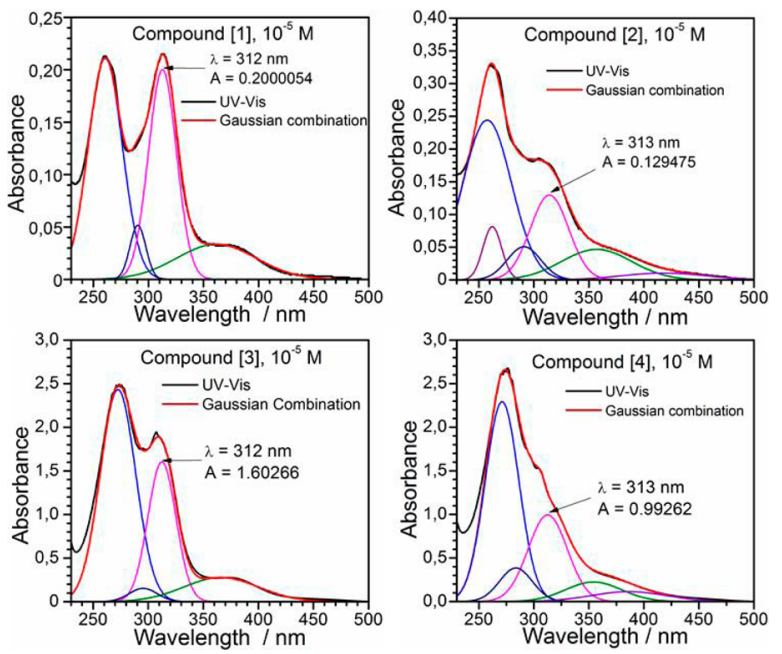

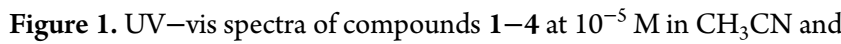
the results of the line fitting with gaussians.
304-314 nm (pink curves in Figure 1) with those from the respective monomers $\mathbf{1}$ and $\mathbf{2}\left(\varepsilon_{0}\right)$. The number of COSAN and FESAN units fits very well with the theoretical ones, corroborating the complete functionalization of OVS (Table S1). These results, along with the NMR spectra, establish the presence of eight metallacarboranes in the final POSS materials 3 and 4.

Improvement in the thermal, mechanical, and oxidative resistance of polymers and composites after the incorporation of silsesquioxanes is known. ${ }^{7}$ Furthermore, materials incorporating boron clusters have a high thermal stability. ${ }^{35,42,43}$ In this line, thermogravimetric analysis (TGA) of $\mathbf{3}$ and $\mathbf{4}$ under argon shows a thermal behavior very different from that of nonfunctionalized OVS (Figure S3). The pristine OVS shows an $82 \%$ weight loss near $290^{\circ} \mathrm{C},{ }^{44}$ whereas both 3 and 4 undergo a very low weight loss between 350 and $600{ }^{\circ} \mathrm{C}$, and after heating to $900^{\circ} \mathrm{C}$, around $88 \%$ of the initial weight was recovered. Compounds 3 and 4 contain $43 \%$ of the organic part, while the percentage of hydrogen would correspond to $7.6 \%$; therefore, we could interpret that after thermal treatment only $\mathrm{H}_{2}$ and a small percentage of the organic part was lost. The former thermal studies confirm the relevance in terms of the thermal stability of incorporating anionic metallacarboranes in the POSS cage.

Considering the reversible redox electroactivity of metallacarboranes, similar to $\mathrm{Fc}$, we aimed to investigate the electroactivity of these materials and their performance in the ET process by CV (Figure 2). Contrary to the poor solubility of the Fc-containing POSS, ${ }^{17} \mathbf{3}$ and $\mathbf{4}$ show very good solubility in organic solvents, so that the $\mathrm{CVs}$ were carried out in dry $\mathrm{CH}_{3} \mathrm{CN}$ at $10^{-3} \mathrm{M}$ for 1 and 2 and $1.25 \times 10^{-4} \mathrm{M}$ for 3 and 4 , using a three-electrode setup and tetrabutylammonium hexafluorophosphate $(0.1 \mathrm{M})$ as an inert electrolyte. Compounds $\mathbf{1}$ and 3 show a redox potential near $-1.74 \mathrm{~V}$ vs $\mathrm{Fc}\left(\mathrm{Co}^{3+/ 2+} \text { in COSAN }\right)^{23}$ whereas for 2 and 4 , the pair appears around $-0.74 \mathrm{~V}\left(\mathrm{Fe}^{3+/ 2+}\right.$ from FESAN). ${ }^{27}$

Despite 3 and 4 bearing eight metallacarboranes each, they exhibit only one redox process in the CV. Besides, no shift in $E^{0}$ is observed between the monomer and the POSS derivative, ${ }^{45}$ which indicates that all units act independently and that there is no electronic communication between the electroactive parts. A similar behavior was observed for octasilsesquioxanes functionalized with eight ferrocenes ${ }^{17}$ and other dendrimers containing 

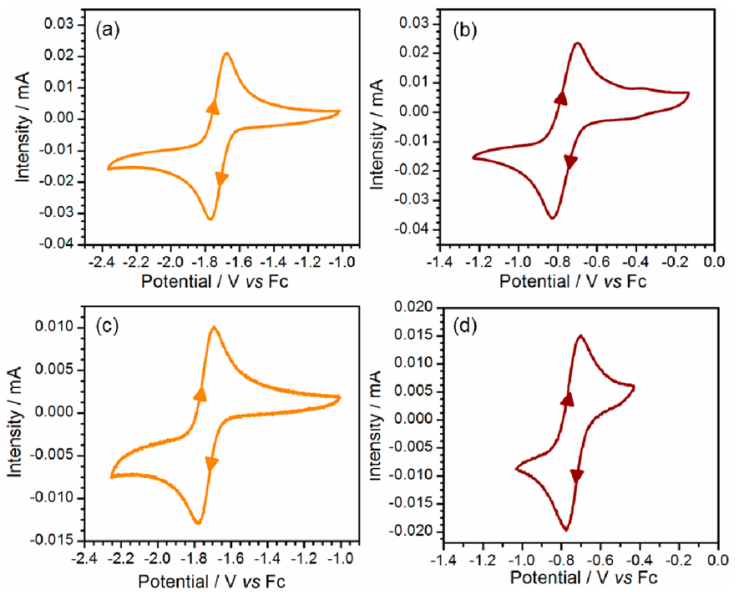

Figure 2. CVs of (a) 1, (b) 2, (c) 3, and (d) 4 in $\mathrm{CH}_{3} \mathrm{CN}$ at $300 \mathrm{mV} / \mathrm{s}$ and $\mathrm{Fc}$ as the internal reference.

ferrocenes or cobaltocinium. ${ }^{4}$ However, for larger globular molecules, all redox-active moieties could not simultaneously be in contact with or in proximity to the electrode. The fact that all eight electroactive members can interact with the electrode implies that the whole molecule has a dimension that permits ET to all of them simultaneously, either by the tunnel effect or due to the rapid rolling of molecules on the electrode surface. ${ }^{46}$ Apparently, the size, shape, and charge of metallacarboranes do not exert any influence on this feature. To learn about the dimensions of compounds $\mathbf{3}$ and $\mathbf{4}$, we first determined diffusion coefficients $(D)$ and later hydrodynamic radii $\left(R_{\mathrm{H}}\right)$. The $D$ values were obtained by the Randles-Sevcik equation $\left(D_{\mathrm{CV}}\right)$ and pulsed-field-gradient spin-echo NMR techniques $\left(D_{\mathrm{NMR}}\right)$. The Randles-Sevcik method requires us to carry out CVs, under the same conditions as previously pointed out, at different scan rates (see the SI). ${ }^{47} D_{\mathrm{NMR}}$ was performed in $\mathrm{CD}_{3} \mathrm{CN}$ solutions (concentrations of ca. $10^{-2}-10^{-3} \mathrm{M}$ ) at $298 \mathrm{~K}$; as a reference, we also measured $D_{\mathrm{NMR}}$ for the starting OVS and pristine COSAN. Unfortunately, the large broad signals observed in the ${ }^{1} \mathrm{H}$ NMR spectrum of the pristine FESAN prevent the measurement of $D_{\mathrm{NMR}}$. The results (Table S2) indicate that the $D_{\mathrm{CV}}$ values for $\mathbf{1}$ and 2 are 2.5 and 3 times smaller with regard to $D_{\mathrm{NMR}}$ values, whereas the difference is between 37 and 39 times smaller for 3 and 4.

Kaifer et al. described a methodology to relate the $D_{\mathrm{NMR}}$ and $D_{\mathrm{CV}}$ values in noncharged Fc-containing dendrimers $\left(D_{\mathrm{CV}}=\right.$ $\left.1.04 D_{\mathrm{NMR}}\right) .^{48}$ However, this method does not fit our results probably because of the stronger interaction of the anionic metallacarboranes with the electrolyte, ${ }^{20,21}$ which prevents good diffusion of our molecules. Regarding the discrepancies between $D_{\mathrm{CV}}$ and $D_{\mathrm{NMR}}$ values and the fact that the $R_{\mathrm{H}}$ value for OVS calculated from $D_{\mathrm{NMR}}(5.49 \AA)$ is in good agreement with that reported for the crystal structure $(5.66 \AA),{ }^{49}$ the $R_{\mathrm{H}}$ values for $1-$ 4 were calculated by the Stokes-Einstein equation using $D_{\mathrm{NMR}}$ values and assuming spherical shapes (Table 1). Compounds 1 and 2 show sizes of around 5-5.5, , whereas POSSs 3 and 4 have $R_{\mathrm{H}}$ values of 16.2 and $17.0 \AA$, respectively. These results indicate that the sizes of $\mathbf{3}$ and $\mathbf{4}$ are adequate to simultaneously perform the redox process of the eight peripheral metallacarboranes. ${ }^{50}$

To confirm the simultaneous reduction of the eight metallacarboranes, 8 equiv of sodium naphthalenide as the reducer was added to a $3 \mathrm{mg}$ solution of $\mathbf{4}$ in dry tetrahydrofuran, obtaining a pinky solid (inset in Figure S5). ${ }^{11}$ B NMR after reduction of 4 confirms that all of the FESANE units have been reduced, from
Table 1. Experimental $D_{\mathrm{NMR}}$ and Estimated Hydrodynamic Radius of 1-4 in $\mathrm{CD}_{3} \mathrm{CN}$ and $298 \mathrm{~K}$

\begin{tabular}{lccc} 
compound & molecular weight, g/mol & $D_{\mathrm{NMR}}, \mathrm{m}^{2} / \mathrm{s}$ & $R_{\mathrm{H}}, \AA$ \\
OVS & 632.8 & $1.148 \times 10^{-9}$ & 5.49 \\
cosane & 456.67 & $1.549 \times 10^{-9}$ & 4.07 \\
fesane & 453.58 & & \\
1 & 604.13 & $1.175 \times 10^{-9}$ & 5.37 \\
2 & 601 & $1.259 \times 10^{-9}$ & 5.01 \\
3 & 5241.7 & $3.89 \times 10^{-10}$ & 16.2 \\
4 & 5217 & $3.72 \times 10^{-10}$ & 17.0 \\
\hline
\end{tabular}

the paramagnetic $\mathrm{Fe}^{3+}$ to the diamagnetic $\mathrm{Fe}^{2+}$ (Figure S5), ${ }^{36}$ showing new resonances from 19 to $-38 \mathrm{ppm}$, including the signal at $18.30 \mathrm{ppm}$ typical for $\mathrm{B}-\mathrm{O}$ in diamagnetic metallacarboranes. ${ }^{51}$ This result corroborates the simultaneous reduction of all of the metallacarboranes.

In conclusion, two new polyanionic and electroactive hybrids based on octasilsesquioxanes bearing eight COSAN or FESAN units are developed and fully characterized. The grafting of metallacarboranes to OVS produces an outstanding thermal stability on the final hybrids. Remarkably, these materials exhibit high solubility in organic solvents that could be modified by changing the cation nature. Electrochemical studies show that the peripheral metallacarboranes act as independent redox units and simultaneously undergo the redox process, providing insight into ET in dendrimers. This feature also brings an additional advantage in the preparation of materials for catalyst, additives, or sensor applications.

\section{ASSOCIATED CONTENT}

\section{S Supporting Information}

The Supporting Information is available free of charge on the ACS Publications website at DOI: 10.1021/acs.inorgchem.6b02394.

Experimental details, the Randles-Sevcik equation, NMR spectra, TGA data, CV, UV-vis data, diffusion coefficients, and ${ }^{1} \mathrm{H},{ }^{13} \mathrm{C}$, and ${ }^{11} \mathrm{~B}$ NMR, IR, and MALDI DOSY experiments (PDF)

\section{AUTHOR INFORMATION}

\section{Corresponding Author}

*E-mail: rosario@icmab.es.

ORCID

Francesc Teixidor: 0000-0002-3010-2417

Rosario Núñez: 0000-0003-4582-5148

Notes

The authors declare no competing financial interest.

\section{ACKNOWLEDGMENTS}

We acknowledge support by MINECO [Grants CTQ201344670-R, CTQ2012-32436, and CTQ2015-64436-P and the "Severo Ochoa" Program for Centers of Excellence in R\&D (SEV-2015-0496)] and Generalitat de Catalunya (Grant 2014/ SGR/149). J.C.-G. thanks to the CSIC for an intramural grant. V.S.-A. thanks MICINN (Grant CTQ2010-16237) for the FPI grant.

\section{REFERENCES}

(1) Astruc, D.; Ruiz, J. The Redox Functions of Metallodendrimers. J. Inorg. Organomet. Polym. Mater. 2015, 25, 2-11. 
(2) Astruc, D.; Ornelas, C.; Ruiz, J. Metallocenyl Dendrimers and Their Applications in Molecular Electronics, Sensing, and Catalysis. Acc. Chem. Res. 2008, 41, 841-856.

(3) Caminade, A.-M. Inorganic dendrimers: recent advances for catalysis, nanomaterials, and nanomedicine. Chem. Soc. Rev. 2016, 45, 5174-5186.

(4) Ceroni, P.; Credi, A.; Venturi, M. Electrochemistry of Functional Supramolecular Systems; Wiley: Hoboken, NJ, 2010.

(5) Sulaiman, S.; Zhang, J.; Goodson, T., III; Laine, R. M. Synthesis, characterization and photophysical properties of polyfunctional phenylsilsesquioxanes: $\left[\mathrm{o}-\mathrm{RPhSiO}_{1.5}\right]_{8},\left[2,5-\mathrm{R}_{2} \mathrm{PhSiO}_{1.5}\right]_{8}$, and $\left[\mathrm{R} 3 \mathrm{PhSiO}{ }_{1.5}\right]_{8}$. compounds with the highest number of functional units/unit volume. $J$. Mater. Chem. 2011, 21, 11177-11187.

(6) Ye, Q.; Zhou, H.; Xu, J. Cubic Polyhedral Oligomeric Silsesquioxane Based Functional Materials: Synthesis, Assembly, and Applications. Chem. - Asian J. 2016, 11, 1322-1337.

(7) Cordes, D. B.; Lickiss, P. D.; Rataboul, F. Recent Developments in the Chemistry of Cubic Polyhedral Oligosilsesquioxanes. Chem. Rev. 2010, 110, 2081-2173.

(8) Hartmann-Thompson, C. Applications of Polyhedral Oligomeric Silsesquioxanes; Springer: Midland, TX, 2011.

(9) Pielichowski, K.; Njuguna, J.; Janowski, B.; Pielichowski, J. Supramolecular Polymers Polymeric Betains Oligomers; Springer: Berlin, 2006; Vol. 201, issue 77, pp 225-296.

(10) Miao, J.; Zhu, L. Topology Controlled Supramolecular SelfAssembly of Octa Triphenylene-Substituted Polyhedral Oligomeric Silsesquioxane Hybrid Supermolecules. J. Phys. Chem. B 2010, 114, 1879-1887.

(11) Díaz, U.; García, T.; Velty, A.; Corma, A. Synthesis and Catalytic Properties of Hybrid Mesoporous Materials Assembled from Polyhedral and Bridged Silsesquioxane Monomers. Chem. - Eur. J. 2012, 18, 86598672 .

(12) Singh, M.; Chae, H. S.; Froehlich, J. D.; Kondou, T.; Li, S.; Mochizuki, A.; Jabbour, G. E. Electroluminescence from printed stellate polyhedral oligomeric silsesquioxanes. Soft Matter 2009, 5, 3002-3005.

(13) Tanaka, K.; Kitamura, N.; Naka, K.; Chujo, Y. Multi-modal 19F NMR probe using perfluorinated cubic silsesquioxane-coated silica nanoparticles for monitoring enzymatic activity. Chem. Commun. 2008, 6176-6178.

(14) Wang, A.; Ornelas, C.; Astruc, D.; Hapiot, P. Electronic Communication between Immobilized Ferrocenyl-Terminated Dendrimers. J. Am. Chem. Soc. 2009, 131, 6652-6653.

(15) Bruña, S.; Nieto, D.; González-Vadillo, A. M.; Perles, J.; Cuadrado, I. Cubic Octasilsesquioxanes, Cyclotetrasiloxanes, and Disiloxanes Maximally Functionalized with Silicon-Bridged Interacting Triferrocenyl Units. Organometallics 2012, 31, 3248-3258.

(16) Herrero, M.; Alonso, B.; Losada, J.; García-Armada, P.; Casado, C. M. Ferrocenyl Dendrimers Based on Octasilsesquioxane Cores. Organometallics 2012, 31, 6344-6350 and references cited therein.

(17) Abad, D. R.; Henig, J.; Mayer, H. A.; Reißig, T.; Speiser, B. Redox-

Active Silica Nanoparticles. 9.1 Synthesis, Electrochemistry, and Diffusion Properties of Caged Octakis( $\mathrm{N}$-ferrocenoyl-3- aminopropyl)silsesquioxane. Organometallics 2014, 33, 4777-4783.

(18) Grimes, R. N. Carboranes, 2nd ed.; Academic Press: Oxford, U.K., 2011; Vol. 16, pp 1053-1082.

(19) Sivaev, I. B.; Bregadze, V. I. Chemistry of cobalt bis (dicarbollides). A review. Collect. Czech. Chem. Commun. 1999, 64, $783-805$.

(20) Brusselle, D.; Bauduin, P.; Girard, L.; Zaulet, A.; Viñas, C.; Teixidor, F.; Ly, I.; Diat, O. Lyotropic Lamellar Phase Formed from Monolayered $\theta$-Shaped Carborane-Cage Amphiphiles. Angew. Chem., Int. Ed. 2013, 52, 12114-12118.

(21) Farràs, P.; Juárez-Pérez, E. J.; Lepsik, M.; Luque, R.; Núñez, R.; Teixidor, F. Metallacarboranes and their interactions: theoretical insights and their applicability. Chem. Soc. Rev. 2012, 41, 3445-3463.

(22) Bauduin, P.; Prevost, S.; Farràs, P.; Teixidor, F.; Diat, O.; Zemb, T. A Theta-Shaped Amphiphilic Cobaltabisdicarbollide Anion: Transition From Monolayer Vesicles to Micelles. Angew. Chem., Int. Ed. 2011, 50, $5298-5300$
(23) Corsini, M.; de Biani, F. F.; Zanello, P. Mononuclear metallacarboranes of groups 6-10 metals: Analogues of metallocenes: Electrochemical and X-ray structural aspects. Coord. Chem. Rev. 2006, $250,1351-1372$.

(24) Núñez, R.; Tarrés, M.; Ferrer-Ugalde, A.; de Biani, F. F.; Teixidor, F. Electrochemistry and Photoluminescence of Icosahedral Carboranes, Boranes, Metallacarboranes, and Their Derivatives. Chem. Rev. 2016, DOI: 10.1021/acs.chemrev.6b00198.

(25) Pepiol, A.; Teixidor, F.; Sillanpää, R.; Lupu, M.; Viñas, C. Stepwise Sequential Redox Potential Modulation Possible on a Single Platform. Angew. Chem., Int. Ed. 2011, 50, 12491-12495.

(26) Lupu, M.; Zaulet, A.; Teixidor, F.; Ruiz, E.; Viñas, C. Negatively Charged Metallacarborane Redox Couples with Both Members Stable to Air. Chem. - Eur. J. 2015, 21, 6888-6897.

(27) Tarrés, M.; Arderiu, V. S.; Zaulet, A.; Viñas, C.; Fabrizi de Biani, F.; Teixidor, F. How to get the desired reduction voltage in a single framework! Metallacarborane as an optimal probe for sequential voltage tuning. Dalton Trans. 2015, 44, 11690-11695.

(28) Juárez-Pérez, E. J.; Viñas, C.; Teixidor, F.; Núñez, R. Polyanionic Carbosilane and Carbosiloxane Metallodendrimers Based on Cobaltabisdicarbollide Derivatives. Organometallics 2009, 28, 5550-5559.

(29) Juárez-Pérez, E. J.; Viñas, C.; Teixidor, F.; Santillan, R.; Farfán, N.; Abreu, A.; Yépez, R.; Núñez, R. Polyanionic Aryl Ether Metallodendrimers Based on Cobaltabisdicarbollide Derivatives. Photoluminescent Properties. Macromolecules 2010, 43, 150-159.

(30) Núñez, R.; Juárez-Pérez, E. J.; Teixidor, F.; Santillan, R.; Farfán, N.; Abreu, A.; Yépez, R.; Viñas, C. Decorating Poly(alkyl aryl-ether) Dendrimers with Metallacarboranes. Inorg. Chem. 2010, 49, 999310000.

(31) Yao, H.; Grimes, R. N.; Corsini, M.; Zanello, P. Polynuclear Metallacarborane-Hydrocarbon Assemblies: Metallacarborane Dendrimers1. Organometallics 2003, 22, 4381-4383.

(32) Masalles, C.; Borrós, S.; Viñas, C.; Teixidor, F. Are LowCoordinating Anions of Interest as Doping Agents in Organic Conducting Polymers? Adv. Mater. 2000, 12, 1199-1202.

(33) Masalles, C.; Llop, J.; Viñas, C.; Teixidor, F. Extraordinary Overoxidation Resistance Increase in Self-Doped Polypyrroles by Using Non-conventional Low Charge-Density Anions. Adv. Mater. 2002, 14, $826-829$.

(34) Sulaiman, S.; Bhaskar, A.; Zhang, J.; Guda, R.; Goodson, T.; Laine, R. M. Molecules with Perfect Cubic Symmetry as Nanobuilding Blocks for 3-D Assemblies. Elaboration of Octavinylsilsesquioxane. Unusual Luminescence Shifts May Indicate Extended Conjugation Involving the Silsesquioxane Core. Chem. Mater. 2008, 20, 5563-5573.

(35) Ferrer-Ugalde, A.; Juárez-Pérez, E. J.; Teixidor, F.; Viñas, C.; Núñez, R. Synthesis, Characterization, and Thermal Behavior of Carboranyl-Styrene Decorated Octasilsesquioxanes: Influence of the Carborane Clusters on Photoluminescence. Chem. - Eur. J. 2013, 19, 17021-17030 and references cited therein..

(36) Plešek, J.; Grüner, B.; Macháček, J.; Císařová, I.; Čáslavský, J. 8Dioxane ferra(III) bis(dicarbollide): A paramagnetic functional molecule as versatile building block for introduction of a $\mathrm{Fe}(\mathrm{III})$ centre into organic molecules. J. Organomet. Chem. 2007, 692, 4801-4804.

(37) Teixidor, F.; Pedrajas, J.; Rojo, I.; Viñas, C.; Kivekäs, R.; Sillanpää, R.; Sivaev, I.; Bregadze, V.; Sjöberg, S. Chameleonic Capacity of [3,3'$\left.\mathrm{Co}\left(1,2-\mathrm{C}_{2} \mathrm{~B}_{9} \mathrm{H}_{11}\right)_{2}\right]^{-}$in Coordination. Generation of the Highly Uncommon S(thioether)-Na Bond. Organometallics 2003, 22, 34143423.

(38) Kim, C.; Jung, I. Preparation of ethynylsilane dendrimers. J. Organomet. Chem. 2000, 599, 208-215.

(39) Viñas, C.; Teixidor, F.; Núñez, R. Boron clusters-based metallodendrimers. Inorg. Chim. Acta 2014, 409, 12-25.

(40) Rojo, I.; Teixidor, F.; Viñas, C.; Kivekäs, R.; Sillanpää, R. Relevance of the Electronegativity of Boron in $\eta^{5}$-Coordinating Ligands: Regioselective Monoalkylation and Monoarylation in Cobaltabisdicarbollide $\left[3,3^{\prime}-\mathrm{Co}\left(1,2-\mathrm{C}_{2} \mathrm{~B}_{9} \mathrm{H}_{11}\right)_{2}\right]^{-}$Clusters. Chem. - Eur. J. 2003, 9, 4311-4323.

(41) Juárez-Pérez, E. J.; Viñas, C.; González-Campo, A.; Teixidor, F.; Sillanpää, R.; Kivekäs, R.; Núñez, R. Controlled Direct Synthesis of C- 
Inorganic Chemistry

Communication

Mono- and C-Disubstituted Derivatives of $\left[3,3^{\prime}-\mathrm{Co}\left(1,2-\mathrm{C}_{2} \mathrm{~B}_{9} \mathrm{H}_{11}\right)_{2}\right]^{-}$ with Organosilane Groups: Theoretical Calculations Compared with Experimental Results. Chem. - Eur. J. 2008, 14, 4924-4938.

(42) Huang, X.; Zhang, Q.; Deng, G.; Mend, Z.; Jia, X.; Xi, K. Benzocyclobutene resin with $\mathrm{m}$-carborane cages and a siloxane backbone: a novel thermosetting material with high thermal stability and shape-memory property. RSC Adv. 2016, 6, 24690-24697.

(43) Núñez, R.; Romero, I.; Teixidor, F.; Viñas, C. Icosahedral boron clusters: a perfect tool for the enhancement of polymer features. Chem. Soc. Rev. 2016, 45, 5147-5173.

(44) Yang, D.; Chang, W.; Yo, R.; Jiang, B. Thermal stability enhancement mechanism of poly(dimethylsiloxane) composite by incorporating octavinyl polyhedral oligomeric silsesquioxanes. Poly. Degrade. Stab. 2013, 98, 109-114.

(45) Compounds 1, 2, and 4 display redox-reversible behavior $\left(\Delta E_{\mathrm{p}}=\right.$ $87 \pm 2 \mathrm{mV}$ ), whereas monomer 3 shows pseudoreversible behavior $\left(\Delta E_{\mathrm{p}}=128 \mathrm{mV}\right)$.

(46) We thank one of the reviewers for this suggestion.

(47) Zanello, P. Inorganic electrochemistry: theory, practice and applications; Royal Society of Chemistry: Cambridge, U.K., 2003.

(48) Sun, H.; Chen, W.; Kaifer, A. E. A Simple Method Based on NMR Spectroscopy and Ultramicroelectrode Voltammetry for the Determination of the Number of Electrons in Faradic Processes. Organsmetallics 2006, 25, 1828-1830.

(49) Voronkov, M. G.; Lavrent'yev, V. I. Inorganic Ring Systems; Springer: Berlin, 1982; pp 199-236.

(50) Ornelas, C.; Ruiz, J.; Belin, C.; Astruc, D. Giant Dendritic Molecular Electrochrome Batteries with Ferrocenyl and Pentamethylferrocenyl Termini. J. Am. Chem. Soc. 2009, 131, 590-601.

(51) Cioran, A. M.; Teixidor, F.; Viñas, C. The effect of a paramagnetic metal ion within a molecule: comparison of the structurally identical paramagnetic $\left[3,3-\mathrm{Fe}\left(1,2-\mathrm{C}_{2} \mathrm{~B}_{9} \mathrm{H}_{11}\right)_{2}\right]^{-}$with the diamagnetic $[3,3-$ $\left.\mathrm{Co}\left(1,2-\mathrm{C}_{2} \mathrm{~B}_{9} \mathrm{H}_{11}\right)_{2}\right]^{-}$sandwich complexes. Dalton Trans. 2015, 44, 2809-2818.

11634

DOl: $10.1021 /$ acs.inorgchem.6b02394

Inorg. Chem. 2016, 55, 11630-11634 